\title{
Poverty, Gender and Primary Education: Experiences of Learners in Elandskop, KwaZulu Natal
}

\author{
Misheck Dube ${ }^{1}$ \\ ${ }^{1}$ Department of Social Work, Life Style Diseases Entity, Faculty of Health Sciences, North-West University \\ (Mafikeng Campus), Republic of South Africa
}

Correspondence: Misheck Dube, North-West University (Mafikeng Campus), P. Bag X2046, 2735, South Africa. Tel: 27-183-892-983. E-mail: Misheckdube@gmail.com

Received: January 25, 2019 Accepted: March 13, 2019 Online Published: April 8, 2019

doi:10.5539/gjhs.v11n5p67 URL: https://doi.org/10.5539/gjhs.v11n5p67

\begin{abstract}
This article discusses the interconnectedness of poverty and gender and learning at primary school level in KwaZulu Natal Province of South Africa. A qualitative study was conducted in two schools in the poverty stricken Elandskop area where data were collected using in-depth face-to-face interviews from purposely selected participants comprising of learners, educators and the headmasters. The aim was to analyse how male and female learners experience poverty, gender role socialisation and the effect on children' bio-psychosocial health of both sexes. While the findings of the study revealed that poverty and gender socialisation of boys and girls have bio-psychosocial negative influences on them, the gender dimension of poverty had the most negative influence on girls. It was found that primary school learners grapple with coping mechanisms when confronted with poverty coupled with limited family and professional support. Gendered family roles and oppressive religious beliefs have been found to have influence on early marriages and teenage pregnancies resulting in school dropouts. The findings of the study imply that school social work is vehemently lacking yet necessary in schools in the area to assist educators in addressing the psychosocial ill-health of learners which educators are less equipped to professionally handle. The study recommends appropriate bio-psychosocial interventions early in the lives of learners to curtail lifelong developmental predicaments.
\end{abstract}

Keywords: poverty, gender, social workers, education, intervention

\section{Introduction}

The problem of poverty in South Africa is not new but the interconnectedness of poverty, gender and primary school education has been given a blind eye by scholars. This is a challenge today more especially to young children, (Paddison, 2017), with the hardest hit being those living in rural areas, where scanty interventions are the order of the day resulting in untold bio-psychosocial problems. The oppressive nature of the communities of KwaZulu Natal Province to children and the girl child, especially in Elandskop, has resulted in extreme polarized gender socialisation of boys and girls which influences violence on boys and early marriages for the girls and teenage pregnancies. It is common wisdom that the legacy of the Apartheid regime left many adult South African Black people in poverty due to unfair policies (Meiring, Kannemeyer, \& Potgieter, 2018). Statistics South Africa (2017) published that about 23 million people are living in poverty in the country. About $64.2 \%$ in 2015 of these people were Black people (Statistics South Africa, 2017). Poverty among the adult population affects mainly their children, (66.8\%), and affects critical developmental spheres with the girl child being the recipient of the unfairness of poverty, gendered development and socialisation within a family. Such challenges are a threat to proper physical, social and intellectual development of the children. Poverty and skewed socialisation of children towards gender roles are vehemently embedded in rural areas where the majority of the Black people live. Common among the rural population of South Africa are the extremes of unemployment, the huge income gap between the "haves" and the "have nots" and the effects of global warming which has resulted in huge droughts recently.

Among the worst affected populations are children with many of them struggling to attend school. Statistics South Africa (2017) reported that $66.8 \%$ of the population affected by poverty were children. In the views of United Nations Children's Fund (UNICEF) (2012) the widespread poverty in South Africa has a significant bearing to violence and negligence against children with necessities such as food, water, shelter and clothing lacking. This 
paper argues that if these critical basic needs are not met for children from poor backgrounds, education is negatively affected and becomes less important despite the need to achieve the much debated Universal Primary School Education (UPE) (Sabates, Akyeampong, Westbrook, \& Hunt, 2010). Social ills such as increased rates of violence and crime and high teenage pregnancy rates are likely to take centre stage and steal the show where young children do not attend school.

Scholars such as Ahmed, Khan, Alia and Noushad (2013) and Psaki (2014) have proven that poverty and gender socialisation have become intricate in ways that pull back the children from poor families to manage navigating their way through education system due to reasons such as early marriages, lack of material things needed for learning especially those that need financial resources. Education of children is made more complex in societies where gender roles are assigned to them and structurally enforced. In South Africa, this happens against the widespread and well pronounced rights of children in the Bill of Rights in the South African constitution. Poverty has been associated with complex matters into lives of children such as anger, truancy, school drop outs, criminal elements and lack of motivation to learn and resulting in educators struggling to handle these problems in schools due to limited professional expertise. In poverty stricken families, gender socialisation of children take precedence, (Ahmed et al., 2013), and parental and family support for education lacks exacerbated by parents' little understanding of the importance of education. Girls are forced into early marriages, (Ahmed et al., 2013, Cummins, 2017), which brings developmental and health complications, (Lawani, Ekem1, Onoh, Eze, Ekwedigwe, Egede, \& Isikhuemen, 2018), especially that people in Elandskop area practice the Shembe religion notorious for polygamous child marriages.

\section{Objectives of the Study}

The objectives in the study were twofold; firstly to determine how poverty and gender affect the bio-psychosocial health and learning of children at primary school level in Elandskop area of KwaZulu Natal Province and secondly to determine the plight and professional support needs of educators of children from poor backgrounds.

\section{Conceptual and Theoretical Framework}

Social work literature and theories that explain the dynamics of poverty, gender and primary school education and bio-psychosocial health per se are scanty. Whilst this study was germane and incumbent in the social work domain, literature is drawn from several disciplines of the social sciences, education and health. This denotes the scarcity of literature in social work of the subject in question and the need for multidisciplinary approach in addressing the plight of children from poor family backgrounds.

Literature shows that South Africa among other countries is one of the most diverse and complex country. The country experiences massive rates of poverty, inadequate education and health services, especially in rural areas. Black Africans in South Africa live in demoralising conditions with lack of access to proper sanitation, housing and proper nutrition which has seen the country marked with service delivery protests on a daily basis. Noteworthy, these conditions have a negative effect on the psychosocial health and education experience of young learners especially coupled with skewed gender socialisation of children from impoverished homes.

\subsection{Central Concepts}

Poverty is a central term in this paper and a number of definitions have been given to the term 'poverty' from different perspectives and academic formalism. It is bedeviled by what it does to people and associated with low income. Poverty is also explained in terms of deprivation, that is, insufficiency in basic human needs such as food, housing clothing, education, medical care and other items required to maintain decent living standard (Spicker, 2015). To describe poverty, the two important terms that need elucidation are absolute poverty and relative poverty. Mack (2016) asserts that absolute poverty is "a condition in which people are deprived of basic shelter, food, drinking water, health, sanitation facilities and clothing" (p.1). In this paper, the contention is that relative poverty is experienced when children from poor backgrounds begin to question and compare themselves from other children from well-up families which breeds despondency among them; a high level predictor of ill psychosocial health among young children.

Scholars agree that poverty is greatly influenced by the individual's background, experiences and environment (Mack, 2016; Spicker, 2015; Zastrow \& Kirst-Ashman, 2013). In that light, poverty in South Africa is experienced differently according to the rural-urban dichotomy, race, age, gender, cultural and religious characteristics with the production of differential experiences of poverty. In terms of psychosocial health, poor children have been associated with increased emotional and social problems (Zastrow \& Kirst-Ashman, 2013). Sadly, such ill psychosocial health associated with poverty can replicate itself from generation to generation. When such ill psychosocial health is accompanied by insufficient education of children, there would be future regeneration of 
poverty contributing immensely to the cycle of poverty

One important concept is the question of gender. As children grow, the messages given to them of "who they are" and "who they can be" is a critical predictor of their future position in society. The World Health Organisation (WHO) (2017) defines gender as a social construction of the "characteristics of women and men including norms, the roles and relationships of and between the groups of women and men", (p.1). Gender changes and is experienced differently from one society to the other whilst there is a concession that it can be changed. This implies that learners in South African communities experience gender differently due to different socioeconomic and cultural backgrounds.

\subsection{Challenges Faced by Poor Leaners}

Learners experience a myriad of challenges emanating from poverty induced circumstances around them. An arsenal of their experiences are amassed with social exclusion, lack readiness to attend school, poor performance at school and an exhibition of a negative attitude towards learning.

\subsubsection{Social Exclusion Aspect}

Booyens and Crause (2012) contend that social exclusion is "a process by which individuals or households experience deprivation, either of resources or of social links to the wider community society", (p.260). Learners from poor backgrounds find it difficult to access basic amenities in their lives most of which are directly linked to their educational needs. Impoverished learners find it hard to access computers, books and school uniforms which are the basic needs for education. Further, learners struggle to get the necessary nutrition for proper development which lands them in ill-health (Kumar, 2018). In their homes, television sets are normally a luxury despite the important educational role played by media to the children. They are socially excluded from others and the world at large. Social exclusion correlates with relative poverty because people are judged to be poor if they are poorer in comparison to other people. Socially excluded children face the problem of lack of knowledge and skills. Education contributes not only to the acquisition of knowledge and skills but also influences the socialization, inclusion and empowerment of individuals which young learners from poor and socially excluded backgrounds lack. Education among other things is a means to personal fulfillment.

Biologically, lack of education on a child reduces the psychological, mental and physical development drastically, (Ahmed et al., 2014; Gaura, 2012), contributing to developmental struggles. Noteworthy, education can also be a source of exclusion if the process of education fails to promote equal participation between the "haves" and the "have nots".

\subsubsection{Lack of Readiness for School}

Research has established that poverty decreases a child's bio-psychosocial readiness for school and for those in school, it reduces their ability to learn due to influences of poor physical health owing to under nutrition, (The BMJ, 2018), unfavourable home life which predisposes them to psychosocial ill-health (Zastrow, 2010). Furthermore, children from poverty stricken families lack psychological motivation to start school and have higher chances of performing poorly once enrolled in schools (Zastrow \& Kirst-Ashman, 2013). Their parents who focus on battling poverty, also are likely to be trapped in lack of proper parental supervision especially on school related matters. In many instances, such parents may not have attained proper education themselves and lack the zeal to motivate their children.

\subsubsection{Reduced Academic Performance}

Iannuzzi (2009) shares that the ill effects of poverty can leak into classrooms unobtrusively and without notice. When learners arrive at school, the expectation from teachers is that they need to demonstrate good performance in their work. Poor learners find it difficult to focus on their school and leave the "chaos" of their home life behind, only to return to it after school. Students raised in poverty are especially subject to psychological stressors, (Zastrow \& Kirst-Ashman, 2013), that undermine appropriate school behaviour and reduce academic performance. Girls exposed to abuse tend to experience mood swings in school, while boys experience learning impairments such as increased curiosity, low critical learning abilities and memory loss.

\subsubsection{Attitudes of Poor Learners Towards Education}

Poverty has been associated with negative attitudes towards learning and the school system and inability to attend school. Unhealthy psychosocial factors such as lack self-confidence and low self-esteem have been observed among poor learners. Payne (2013) attributes such factors as extra aggravating circumstances to children's social circles at school such as exclusion and negative labels. Payne further points to psychologically harmful labels such as aggressive, attention disordered, dropouts, drug abusers as more influential in the attitudes of learners from poor 
backgrounds towards education. In addition, the learner may develop insecurity to attend school and this creates a negative attitude associated with truancy. This paper however takes cognizance of Mapingire (2016 )'s warning that a critical analysis of a wider spectrum of other factors should be considered to determine what influences the attitudes of learners on education in addition to Payne (2013)'s specificity on poverty.

\section{Theoretical Framework}

In conducting the study, a feminist approach was adopted in explaining the experiences of female learners in their gendered education whilst employing a social constructivist theory in the methodology.

\subsection{Feminist Theories}

Feminist theories have long argued that society have a tendency of oppressing the weak and reducing them to a subordinate population. Feminists argue that these differences begin at birth and continue throughout the lifespan of people. The type and colour of clothes families buy for the boys and girls differ as well as the type of dolls they play with which denote oppression of girls from an early age (Teater, 2010). Central to the feminist theories is the gender schema theory which examines how society influences individuals to view gender with specific lens and the establishment of roles that are attached to a specific gender (Teater, 2010). In this children are taught and conditioned to learn specific roles according to gender which shape their future development of self. Various feminist theories appear in literature, but this paper endorses the explanations of radical and liberal feminism in highlighting poverty and the gendered education of children in primary schools in KwaZulu Natal Province.

Radical feminists condemn power relations in the society and dominance of men in oppressing women and girls using structural and social systems that limit their advancement and entrenching poverty. They critique cultural norms and values such as the Shembe religion in KwaZulu Natal emboldened in society for oppressing women and girls which limits their choices and assert that there is need for lessening systematic and institutionalised gender oppression for women and girls to advance in society without which women and girls will remain subordinate among societal members.

Liberal feminist spell freedom for women and girls in society and demonise society for not according women and girls equal opportunities with men and boys. The society is seen to have a false belief that women and girls are naturally less intelligent physically weaker than men (Tong, 2009, p. 2). The argument of the liberal feminists have been supported in this paper in that KwaZulu Natal communities need to provide the same opportunities to women and girls as it does to men and boys. Tong (2009) argues that society ties gender and sex together and assigns roles to girls and women that are traditionally feminine and less beneficial to current advancements in society. The liberal feminists raise an important suggestion which resonates with the contention of this paper that women and girls should be given the freedom to self-actualise rather than be forcibly entangled in social oppression such as forced early marriages organised religiously or to "bail-out families" from poverty.

\subsection{Social Constructivist Theory}

The social constructivist theory was critical in this study as it helped in understanding how primary school learners experience poverty, gender and education. The point of departure in a social constructivist theory is that people construct reality and come to 'know the world by interacting with other people, organisations and institutions' (Teater, 2010, p. 12). The theorists acknowledge the fact that reality and experiences are different from one person to another and each person's experiences of social and cultural values is critical and essential in understanding their view of the world. Thus the social constructivists argue that there is no better way of understanding what people experience if they do not recount their experiences within a historical and cultural context. The theorists concede that the social environment plays a significant role in shaping the experiences of children and positioning their future success or failure within a broader society. The theory was central in this study in that a qualitative explanation of the experiences of children and educators illuminated on how children experience poverty and gender in Elandskop.

\section{Methods and Materials}

The study used a qualitative approach to collect first-hand information obtained directly from participants (Miles \& Huberman, 2009). Data were collected from the participants within their environment so that participants could feel free to recount and share their lived experiences.

The population of the study comprised of the learners and the staff members of Nana and Lala Primary Schools (not real names), in Elandskop in KwaZulu Natal. Most of the learners in these schools come from poor family backgrounds. Educators of the schools have the plight of teaching learners from poor family backgrounds and hence have better information on how poverty affects the learners. Non-probability purposive sampling technique 
(Denscombe, 2010; Padgett, 2017; Whittaker, 2012) was employed to get a sample of grades seven, six and four learners to participate in the study. The aforementioned, (grades seven, six, and four), learners had a reasonable thinking capability to respond to questions in the study and have experienced poverty for the longest time while learning. Educators became participants so that they could provide their work experience with learners from poor backgrounds. The Headmasters of Nana and Lala Primary Schools were selected as they oversee learning in their schools and have overall information on how the learners are affected by poverty, gender and learning at the schools. The researcher purposely (Denscombe, 2010; Padgett, 2017) selected a sample size of twenty participants, however data saturation was experienced with eighteen participants who eventually become part of the study. The aim was to obtain in-depth information on the interplay of poverty, gender and learning rather than to obtain quantity and less valuable information for the study. Many sections of the South African communities have improved poverty alleviation strategies, adhere well to rights of children and have different religious practices. Elandskop was purposely selected to indicate disparities of development and democratic achievements of the South African communities in observing the rights of children. The area is characterised by skewed gender socialisation, poverty and cultural and religious practices that oppress girls. Thus the area was suitable for conducting the study to indicate the developmental leg and bring the debate of rights and democracy into light. Padgett (2017) suggests that when determining sample size, the researcher needs to go "an inch wide and a mile deep," suggesting that a smaller number is desirable for collection of intense information in a qualitative study, (p.70). There were four (two female, two male) learners from each of the following grades per school; grade seven, six, and four; that were interviewed from the two schools. For grades one and two, four teachers participated in the study with two teachers from each school being part of the study because the leaners were too young to participate and answer questions. There were also two headmasters (one per school) that participated in the study. This brought the sample size to eighteen which was qualitatively adequate to provide in-depth information for this study. The researcher could not interview grades five as initially planned due to their commitments in their academic activities and timetable congestion until the time that data saturation was reached.

\subsection{Instrumentation and Data Collection}

Three separate interview schedules were used to collect data on individual face-to-face semi structured interviews administered on selected learners, educators and the Headmasters. The rationale for using face-to-face interviews was that the researcher sought to find first-hand information from participants and also to observe non-verbal cues during the interviews. Face-to-face interviews, (D'Cruz \& Jones, 2014; Whittaker, 2012), were used to systematically collect data from the participants following predetermined themes that guided the questions on the three interview schedules. The interviews helped the researcher to understand the experiences of the learners, including the sensitive issues that learners do not often talk about. This also helped the educators to express themselves fully during the interviews. Open ended question and probes were used to facilitate unrestricted expressions and responses from the participants.

Data were analysed thematically from the information provided by the participants. Hardwick and Worsely (2011) describe data analysis as 'creating order from chaos', (p.114). Thematic data analysis was defined by Whittaker (2012) as 'identifying, analysing and reporting patterns (themes) in data' (p.96).

\subsection{Ethical Considerations}

Brynard, Hanekom and Brynard (2014) enlighten that ethics relates to what conduct is 'right or wrong' on the part of the researcher. Consistent with research ethics, the researcher obtained permission from the parents of the leaners and gained access to conduct research from the Headmasters of the two schools (D'Cruz \& Jones, 2014; Silverman, 2010). Congruous with the ethic of voluntary participation, the participants were also not coerced to take part in the study. The learners were given ballpoint pens as token of appreciation for being interviewees. Parental permission to engage their children in the study was sought and adolescent informed consent was sought from the learners before interviews were conducted. The identity of individuals and personal information was not obtained. The real names of the primary schools that participated in the study were not used. Nana and Lala Primary Schools are pseudo names of the schools. This ensured the ethical obligation of confidentiality and privacy of the participants, (Hardwick \& Worsley, 2011), as required and concomitant with ethical conduct of research.

\section{Discussion of Findings}

The findings as discussed emanated from the interviews with the headmasters of Nana and Lala Primary Schools, educators and lastly the learners. The headmasters provided an overview of the experiences of the learners as leaders of the schools whilst the educators constantly engage the learners in classes and bring the classroom experiences of the psychosocial challenges of learners. The learners bring their personal experiences and realities, 
home and social circumstances that impact on their psychosocial health and educational aspirations.

\subsection{Findings From the Interviews With the Headmasters}

Interviews with the Headmasters, yielded that bio-psychosocial and educational factors are prominent among the challenges faced by learners from poor family backgrounds. An arsenal of the prominent challenges included hunger, lack of adequate clothing and school drop-outs. In the current context of widespread social security in South Africa, a juxtaposed and paradox finding was that hunger was a dominant challenge experienced by the learners in the schools as most parents in the area were not working and therefore found it difficult to provide adequate and nutritious food (Paddison, 2017) for their children. The headmasters confirmed this:

'I have had cases where learners reported that their lunch was stolen by a child who has not eaten for over the past 8 hours', (Headmaster of Lala Primary School).

'A child fainted during lunch break. The cause of this was that the child had not eaten for two days', (Headmaster of Nana Primary School).

The implication of these findings are that hunger has serious health issues for young children in primary schools with the possibility of death (Paddison, 2017). This results into eminent poor health and psychosocial developmental challenges needed for normal functioning. For those that soldier on and battle the ordeal, they feel fatigued, lack concentration in classes and the needed energy to meet the mental demands of learning which has negative implications on academic performance. It is not imaginary that proper and adequate clothing is one of the greatest needs of children. Evident to this contention was the revelation from the headmaster who indicated that children from impoverished backgrounds do not dress adequately. They come to school inappropriately and humiliatingly dressed. The headmaster of Nana Primary revealed this:

I have seen learners coming to school bare footed, no jersey, tight and uncomfortable school shirt in some instances they do not wear school shirts at all. Such learners shiver and they suffer from the cold which makes it difficult for them to pay attention in class this in turn negatively affects their academic performance'.

From this finding it can be argued that psychosocially, the appearance of a child affects the child's esteem towards education. Further, when a learner notices that he or she is different from other learners the feeling of embarrassment and depression is stimulated. Often learners withdraw from maintaining social relationships with their peers and further aggravates poor performance or less motivation to learn (Valdez, 2015). An inappropriately dressed child, especially in cold weather, is negatively affected making it difficult to pay attention in class. Drop-outs from school then become inevitable as young learners find it difficult to cope with the experiences of attending school either inappropriately, partially or differently dressed. So this has developmental challenges for the learners. Scholars have noted that education is a key to development and transformation and without it children may find it difficult to develop socially, economically and politically (Ahmed et al., 2013; Obeng-Denteh, Yeboah, \& Monkah, 2011; Paddison, 2017).

A globally condemned phenomenon found by the study was that gender roles negatively affect female children's education (Ahmed etal, 2013). In the two schools, the study revealed a higher dropout rate among female learners compared to their male counterparts. Though unconstitutional in South Africa, in Elandskop, families tend to overburden female learners with chores at home and often such girls are too young to take huge responsibilities. Some take care of their siblings when their parents succumb to Human Immunodeficiency Virus (HIV) and Acquired Immunodeficiency Syndrome (AIDS), a phenomenon very common in KwaZulu Natal Province due to the high levels of HIV cases (Cullinan, 2013). This causes a huge problem on female learners as they are inhibited from getting education that improves their lives and possibly takes them out of the cycle of poverty and contributes to their personal development. At a more pragmatic level, UNICEF (2012) sees poverty in families being a steering factor in widespread "violence against children", (p.18) such as what children from Elandskop experience.

Female learners attending school at Nana and Lala Primary Schools find themselves with family responsibilities at their homes at a young age, (Psaki, 2015), at the expense of the education, so inconsistent with the Children's Act of 2005 of South Africa. This is aggravated by the religion (Ahmed et al., 2013), of Shembe in KwaZulu Natal which mandates early marriages among young female congregates mostly to older males within the religious group. The religion is so strong in the area such that reporting such practices and abuse of children is protected by the religious group and often emotional and challenging. Economically, the families mitigate poverty and inability to send girls to school by arranging marriages to meet the stinging family financial demands and poverty. This practice is directly a victim of feminist argument such as liberal feminists who argue that girls are forced into social roles which are deemed to be feminine. They militate and oppose the society and families on their misconception of assigning inferior roles to girls which they see as an oppression that must be ended. This is what the headmaster 
of Lala Primary revealed:

'I have had cases of three grade seven learners who dropped out of school because they had to become wives as per Shembe Church arrangement with families'.

Whilst female learners drop out of school for carrying out home chores and early arranged marriages, males learners are not spared from school dropout either. Boys are forced to seek employment due to difficult family circumstances. This deprives the learners of their desperately needed education and re-engineers the continuation of the cycle of poverty. The overly concerned headmaster of Nana Primary School had this to say:

'The most devastating explanation of a learner dropping out of school was that, the family circumstances forced a child to drop out of school to seek employment in order to survive'.

It is an astonishing fact that poverty in Elandskop area influences child labour because families that struggle financially supplement their income by engaging children to participate in paid cheap labour. Contrary to the findings by Sabates et al. (2010) that learners have higher chances of completing lower secondary school in South Africa, in the study area, it was found that parents take their children out of school and force them to seek employment to supplement their home income. Child labour is illegal in South Africa and deprives children of their social functioning, physical and mental development (Gaura, 2012). Eventually, it influences repetition of the cycle of poverty within families and the larger society. This raises questions on the pragmatic application and observation of children's rights in Elandskop. Children's rights seem to be at higher risks and vulnerability to be broken where poverty is symptomatic in families and minimal professional intervention is realised to ameliorate the situation. Besides, child labour has negative bio-psychosocial developmental issues for children.

\subsection{Findings From the Interviews With Educators}

Educators have direct contact with the learners on a daily basis and provided their experiences with learners from poor background. The study had interesting findings from the interviews with the educators. Learners from poor background have been found to have disruptive behaviour in classrooms. They tended to disturb learning activities which then forced educators to carefully manage such behaviour for the benefit of fellow learners. This is a practical fragile situation for teachers who have meagre professional training to handle behavioural problems of learners. It further compromises learning which is a gap that should be closed by use of the services of a professional school social worker or child psychologist. This is what the educators had to say:

'Poor learners are at an increased risk of physical, social and psychological problems and because they are under a lot of strain they tend to be troublesome', (Grade 1 educator from Nana Primary School).

'As educators we are faced with a challenge of dealing with disruptive behaviour. When a learner is disruptive, this has a negative impact on a lesson because the teacher is compelled to stop teaching and reprimand the troublesome learner by doing so everybody suffers', (Grade 2 educator from Lala Primary School).

From the declaration by educators, it can be deduced that, the disruptive behaviour of poor learners is caused by the lack of nurturing guidance and supervision from their parents and so they seek attention wrongly. The negative behaviour a learner exhibits is symptomatic to the psychosocial strain that the learner experiences.

Not only does poverty contributes to school dropout, early marriages, (Ahmed et al., 2013), and cheap child labour, it also contributes to absenteeism from school for those still in school. This cuts across both genders of learners. The learners lose out on classes which contributes to poor school-related performance (Mosibudi, 2012; Teixera, 2014). It was found that educators also experience challenges of improving academic progress of learners from poor backgrounds by providing extra lessons for them to catch up with other classmates. A Grade 2 teacher from Nana Primary school revealed this:

'The problem of absenteeism is quite prevalent in Nana Primary. Poverty is the most dominant factor on absenteeism, this remains a huge challenge for educators because they must re-teach the previous lesson to accommodate those learners that were absent'.

Repeating the previous lessons done by teachers, wastes progressive teaching time of the educators and tends to be boring to learners that attend school regularly. Time wasted negatively affect educators' planning and work that must be covered for the entire syllabus, therefore educators fall behind schedule. In the views of Mosibudi (2012) learners' absenteeism has a negative effect on dynamic teaching and learning environments and smooth running of classes. This has a demotivating factor on the educator and is unfair to frequently attending learners for repeating lessons several times.

The attitude of the learners from poor backgrounds towards education yielded interesting and contrasting findings. In some findings the learners were unexpectedly highly motivated to learn while in other findings they had a 
negative attitude towards education. The educators revealed these contrasting findings during the interviews:

'Attitude of poor learners varies according to their family background. In my class I have a learner living in extreme poverty but her attitude towards education is positive. I admire her resilience and her attitude because she does not allow her circumstance to deprive her of getting educated', (Grade 1educator from Nana Primary School).

'Majority of learners in my class lack discipline and are disrespectful. Their attitude towards learning further aggravates the problem of poor academic performance. Such learners ignore the siren, they come late to class and disturbs the learning process. It is frustrating to educate in such environment. Very often these learners possess a negative attitude because they lack motivation to learn', (Grade 2 educator from Lala Primary school).

Scholars have underscored that poor learners have a negative attitude towards learning (Payne, 2013; Zastrow \& Kirst-Ashman, 2013). Learners lack motivation to learn and sometimes they behave as a reaction to the negative labels they receive from their fellows at school. Negative attitudes discourage, limit and prevent learning. Such attitudes therefore resist change and discourage growth, which can stunt the learning to a large extent. In other instances, learners are encouraged and have great enthusiasm towards their education. This is in sharp contrast to the negative behaviour other learners reportedly displayed. In view of highly motivated learners, Siribaddana, (2012) holds that learners can open their minds and get rid of the self-imposed limitations that could negatively influence the learning process and as such demonstrate a highly positive attitude towards learning. The implications for these findings have led the researcher to view it in two ways. Firstly that learners may feel overwhelmed by poverty and lose focus if guidance is not provided to facilitate re-focusing on their educational goals. Secondly, learners have the ability to take poverty as a motivator to work hard at school in order to change their future lives. This therefore calls for the educators to provide an enabling and facilitative environment to their learners so that learners realise their future goals. However, the question that can be raised and needs critical thinking is whether the educators have the professional capacity to facilitate psychological re-focusing of learners towards their education without the professional expertise of social workers who are currently not available in these schools.

\subsection{Findings From the Interviews With Learners}

The interviews with the learners focused on their own understanding of education and its importance and their brief family backgrounds which have direct impact on their bio-psychosocial health.

\subsubsection{An Understanding of Education to the Learners From Poor Backgrounds}

Twelve learners gave their views on the meaning attached to education. Of the twelve learners, the majority (ten) relate education to success in their lives. They had an understanding that education can enable them to improve their lives in the future. They associated education with better jobs and achievement. This is what Learner 2 from Nana had to say:

'Education means going to school to learn about things that will help to achieve great things in life and provide a secure future for a person'.

Only one learner had a different understanding of education in life and contrastingly associated it with lack of success. The above findings confirm that learners understand the benefits of education and as such drives them to achieve better in their learning activities. However, the study has also presented evidence that some learners may be unfortunate to be swerved off from focusing on education by poverty and search for work in an endeavour to improve immediate poor home circumstances. This supports the contention of the social constructivist theory that individuals experience realities differently and that it is only through engagement with them that their individual experiences can be comprehended (Teater, 2010).

\subsubsection{The Importance of Education to Learners From Poor Backgrounds}

The importance of education to the learners also yielded interesting results from the interviews. The learners from poor backgrounds gave honest responses on whether they value education in their lives. Many of the learners (ten out of twelve) indicated that education was important to them because they related education to finding better jobs and better social status in their communities. From the learners who regarded education as important in their lives, this is what Learner 4 from Lala Primary School revealed during the interviews:

'Yes education is important to me because, if I get educated I will find a job and earn a large amount. I will be able to buy things I like that I never had. If I am educated my social status will be respected'.

Solomons and Fataar (2011) also pick up the argument adding that education has an imprint in adding citizenship values on the learner. The authors further argue that education adds to nation building through active participation 
of the learners in matters of their communities. On the contrary, some learners resent school apparently due to observational learning from their parents especially from families with uneducated parents who never participate in the learning activities of their children. While some of the uneducated parents may try to send their children to school but the learners find education having little meaning in their lives. Others find the school environment unfriendly to them as they cannot associate well with fellow learners. It is clear that from home-to-school environments, learners from poor backgrounds experience demotivating factors to learn. This is what the learners revealed in the study:

'I do not like to go to school. My parents are not educated but they can survive, I do not need education to survive. My parents force me to go to school it is not my will', (Learner 1 from Lala Primary School).

'I do not think education is important because I do not have friends at school because I feel that they are better than me when I am with them'. (Learner 2 from Lala Primary School).

As has been found by the study, children from poor families lack control of their education, are anxious and may be less motivated to learn. With lack of control over their education and little motivation to learn, it becomes inevitable to lose focus and drop out of school with girls getting married early (Ahmed et al., 2013). This indicates that children struggle to pursue their goals in life when faced with difficult environmental circumstances that militate their educational goals (Paddison, 2017). This is when professional social work needs to be made use of in schools to deal with such psychosocial struggles and apathy towards learning.

\subsubsection{The Influence of Family Background}

It is argued that the foundation of learning for children is within the family. The family background has tremendous influence on the education of children and their attitude towards it thereof. Research argues that a home for a child is the most crucial social setting that is conducive to grooming and supporting children with school work (Payne, 2013). Disorganised family background and poverty stricken families are less favourable environments for proper upbringing of learners (Zastrow, 2010; Zastrow \& Kirst-Ashmen, 2013). Of the twelve learners that participated in the study, the majority (ten) indicated that they have been badly affected by family disorganisation such as fights and congestion in homes. Children become stressed, anxious and fight for meagre resources leading to nutritional deficiencies, (Amedeker \& Obeng-Denteh, 2011), consequently affecting the development of their brain, a factor resulting into a multitude of behavioural problems (Zastrow \& Kirst-Ashman, 2013). Low level of education among parents of learners from poor backgrounds has been found to lower the love for education for their children. Given the education system of South Africa which relies heavily on the involvement of parents, therefore learners with uneducated parents find it hard to do their home works. Parents are unable to assist the learners at home and are therefore hardly involved in their work (Menheere \& Hooge, 2011). This affects performance at school and reduces the zeal for education of the learners which has negative ripple effects on optimal bio-psychosocial development of children.

\section{Conclusions and Recommendations}

The findings of the study have shown that there is significant interplay of poverty and gender towards young learners' education at primary school level. Learners from poor backgrounds, especially girls are negatively affected by their religious and social backgrounds. It is concluded that the poor home circumstances and fervent adherence of parents to oppressive religions affect primary school learners negatively and contributes towards school drop outs and unwanted early marriages. This has negative effects towards children's bio-psychosocial health manifesting in children grappling with physical, psychological and social development. Learners have fragile coping mechanisms and without family support at home and professionalised interventions in schools, they are forced to drop out of school which for them is an easy way out of the humiliating and uncomfortable circumstances they find themselves in, which has the potential to unintentional reproduce the cycle of poverty in their families. There is also natural strength and resilience for some learners who, despite the odds, soldier on and continue with education despite difficult circumstances, though their performance could be enhanced if provided with nurturing support from both the families and school environments.

In Elandskop area in KwaZulu Natal, unhealthy and unlawful practices such as early marriages of girls and cheap labour for boys contribute to school dropouts. This explains the skewed cultural and gender socialisation component children undergo in their developmental milestones in KwaZulu Natal. Clearly, conducive environments play a critical role in the education of a child both at home and at school. While the absence of school social workers in schools affects learners directly, this study also concludes that educators are equally affected as they live with the psychosocial ordeal of learners in need of professional help.

Though the study was purposive in nature and based on a specific area, the findings revealed important grounds for 
making essential recommendations. Based on the findings discussed and conclusions reached, it is recommended that:

- The Department of Education in KwaZulu Natal Province of South Africa should consider using the services of School Social Workers to assist educators with a host of psychosocial problems experienced by learners. Apparently there is an enormous lack of professional support from Social Workers especially in the area of the study.

- The current cultural and religious context of the study militates progressive policies applicable in the post-apartheid South Africa. Extensive community education on children's rights and healthy religious practices is needed to curtail gendered education and Primary School dropout of learners, whilst embracing and maintaining inclusive universal education. This will assist in the prevention of early marriages amongst girls and child labour for boys which have enormous bio-psychosocial developmental consequences.

- Bio-psychosocial health practitioners, inclusive of social workers, psychologist and nutritional experts need to support impoverished communities such as Elandskop and to centre practice on distributive justice, gender matters, children's rights, parental skills and mobilise resources needed for supporting healthy bio-psychosocial developmental needs of children.

\section{Competing Interests Statement}

The authors declare that there are no competing or potential conflicts of interest.

\section{References}

Ahmed, S., Khan, S., Alia, M., \& Noushad, S. (2013). Psychological Impact Evaluation of Early Marriages. International journal of endorsing health science research, 1(2), 84-86. https://doi.org/10.29052/IJEHSR.v1.i2.2013.84-86

Amedeker, M. A., \& Obeng-Denteh, W. (2011). Thesis on the causes and effects of female dropouts. Kwame Nkrumah University of Science and Technology: Ghana.

Booyens, M., \& Crause, E. (2012). Excluded from Education and Work: Perceptions of at risk youth. Social Work/Maatskaplike Werk, 48(3), 255-274. http://dx.doi.org/10.15270/48-3-84

Bryanard, D. J., Hanekom, S. X., \& Bryanard, P. A. (2014). Introduction to research (3rd ed). Pretoria: Van Schaik publishers.

Cullinan, K. (2013). KwaZulu-Natal charts gains in HIV despite massive burden. Retrieved from KwaZulu-Natal charts gains in HIV despite massive burden website: https://www.health-e.org.za/2013/10/29/kwazulu-natal-charts-gains-hiv-despite-massive-burden/

Cummins, D. (2017). Teenage Pregnancies and Early Marriages: Research on the Decision-Making Pathways of Young Women in the Municipalities of Covalima, Aileu and Dili. Dili.

Timor-Leste: United Nations Fund for Population Activities (UNFPA). Teenage Pregnancies and Early Marriages: Research on the Decision- Making Pathways of Young Women in the Municipalities of Covalima, Aileu and Dili. Retrieved from https://www.researchgate.net/publication/318672858

D’Cruz, H., \& Jones, M. (2014). Social Work research in practice, (2nd ed). Los Angeles: SAGE.

Denscombe, M. (2010). The good research guide for small-scale social research projects (4th ed). London: MacGraw Hills.

Gaura, D. (2012). Child Labour is Still Missing from the Agenda. Child labour. Child Labour is Still Missing from Agenda. Child labour. Retrieved from http://www.anexcdw.org.za/index.php?option= com_content\&view $=$ category\&layout $=$ blog $\& \mathrm{id}=5 \&$ Itemid $=14$

Hardwick, L., \& Worsely, A. (2011). Doing Social Work research. London: SAGE

Holstein, J., \& Gubrium, J. (2008). The active interview. Thousand Oaks: SAGE Publications Ltd.

Iannuzzi, J. (2009). Effect of poverty on academic Performance. United States: Oxford University Press.

Kumar, G. (2018). What is Poverty and its types? Retrieved from What is poverty and its types website: https://www.jagranjosh.com/general-knowledge/what-is-poverty-and-its-types-1523453034-1

Lawani, L. O., Ekem, N. N., Onoh, R. C., Eze, J. N., Ekwedigwe, K. C., Egede, J. O., \& Isikhuemen, M. E. (2018). The Prevalence and Determinants of Unintended Pregnancies Among Women in Abakaliki, Southeast 
Nigeria. Global Journal of Health Science, 10(10), 65-73. https://doi.org/10.5539/gjhs.v10n10p65

Mack, J. (2016). Absolute and overall poverty. Retrieved from http://www.poverty.ac.uk/definitions-poverty/absolute-and-overall-poverty.

Mapingire, M. (2016) Factors leading to negative attitudes towards learning of mathematics at Secondary School in Kwekwe District. (Bachelor's Degree mini dissertation), Gweru: Midlands State University. http://hdl.handle.net/11408/2974.

Menheere, A., \& Hooge, E. (2011). A review study about the effects of parental involvement on children's school education. Journal for European Teacher Education Network, 1(6), 144-157.

Miles, M., \& Huberman, M. (2009). Qualitative data analysis. London: SAGE Publications Ltd.

Meiring, T., Kannemeyer., C., \& Potgieter, E. (2018). The gap between rich and poor: South African society's biggest divide depends on where you think you fit in: Cape Town: SALDRU, UCT. (SALDRU Working Paper Number 220).

Mosibudi, D. M. (2012). Factors affecting Academic Performance of Grade 12 learners in Mogalakwena Circuit (MA dissertation). Limpopo: University of Limpopo.

Obeng-Denteh, W., Yeboah, E. A., Sam, C., \& Monkah, J. E. (2011). The impact of student and teacher absenteeism on student performance at the junior high school: the case of the Kumasi-metro school district. Cont J Educ Res, 4(1), 7-17.

Paddison, L. (2017). Educating girls: the key to tackling global poverty. Retrieved from https://www.theguardian.com/opportunity-international-roundtables/2017/oct/04/global-poverty-child-marri age-education-girls

Padgett, D. K. (2017). Qualitative Methods in Social Work Research (3r $\mathrm{r}^{\mathrm{d}}$ ed). Los Angeles: Sage.

Payne, R. K. (2013). A Framework for Understanding poverty: A cognitive Approach. Highlands: Aha Process Incl.

Psaki, S. R. (2014). Addressing early marriage and adolescent pregnancy as a barrier to gender parity and equality in education. Background Paper for the 2015 UNESCO Education for All Global Monitoring Report. New York: Population Council.

Sabates, R., Akyeampong, K., Westbrook, J., \& Hunt, F. (2010). Paper commissioned for the EFA Global Monitoring Report 2011, The hidden crisis: Armed conflict and education School Drop out: Patterns, Causes, Changes and Policies. University of Sussex, Centre for International Education School of Education and Social Work.

Silverman, D. (2010). Doing qualitative research: A Practical Handbook. (3rd ed). Los Angeles: SAGE.

Siribaddana, P. (2012). How Attitudes affects the Learning Process. Colombo: University of Colombo.

Solomons, I., \& Fataar, A. (2011). A Conceptual exploration of values Education in the context of schooling in South Africa. South African Journal of Education, (31), 224-232. http://dx.doi.org/10.15700/saje.v31n2a482.

Spicker, P. (2015). Definitions of poverty: twelve clusters of meaning. Retrieved from https://www.researchgate.net/publication/265422363

Statistics South Africa. (2017). Poverty Trends in South Africa: An examination of absolute poverty between 2006 and 2015. Pretoria: Statistics South Africa.

Teater, B. (2010). An introduction to Applying Social Work Theories and Methods. New York: Mc Graw Hill Open University Press.

Teixeira, A. A. C. (2014). The impact of class absenteeism on undergraduates' academic performance: evidence from an elite Economics school in Portugal. Innovations in Education and Teaching International, 53(2), 1-13. http://dx.doi.org/10.1080/14703297.2014.937730.

The BMJ. (2018). Hunger and malnutrition in the 21 st century. Retrieved from http://dx.doi.org/10.1136/bmj.k2238

Tong, R. (2009). Feminist thought: A more comprehensive introduction. Philadelphia, PA: Westview Press.

United Nations Children's Fund. (2012). Violence Against Children in South Africa. Pretoria: Department of Social Development/Department of Women, Children and People with Disabilities/UNICEF. 
Valdez, J. (2015). Effects of Poverty on Children's Education. University of Nebraska - Lincoln: Nebraska College Preparatory Academy.

Whittaker, A. (2012). Research skills for Social Work (2nd ed.). Los Angeles: SAGE.

World Health Organisation. (2017). Gender, equity and human rights. Retried from $\mathrm{http} / /$ www.who.int/gender-equity-rights/understanding/gender-definition/en/

Zastrow, C. (2010). Introduction to Social Work and Social Welfare: Empowering people (3rd ed.). Australia: Brooks/Cole.

Zastrow, C. H., \& Kirst-Ashman, K. K. (2013). Understanding Human Behaviour and the Social Environment. Australia: Brooks/Cole.

\section{Copyrights}

Copyright for this article is retained by the author(s), with first publication rights granted to the journal.

This is an open-access article distributed under the terms and conditions of the Creative Commons Attribution license (http://creativecommons.org/licenses/by/4.0/). 